\title{
Effect of postextrasystolic potentiation on amplitude and timing of regional left ventricular wall motion in ischaemic heart disease
}

\author{
D G GIBSON, E FLECK, W RUDOLPH \\ From the Brompton Hospital, London, and Deutsches Herzzentrum, Munich, Federal Republic of Germany
}

SUMMARY In order to investigate the effects of postextrasystolic potentiation on left ventricular wall motion, the left ventriculograms of 30 patients were digitised frame by frame and regional movement demonstrated by contour displays. Postextrasystolic potentiation caused significant increases in end-diastolic volume, ejection fraction, and peak ejection and filling rates. The amplitude of normally moving segments increased by $5.7 \pm 2.3 \mathrm{~mm}$, regardless of initial amplitude. Hypokinetic segments moved normally if the initial amplitude was greater than $5 \mathrm{~mm}$, and there was a reduced or absent response if $4 \mathrm{~mm}$ or less. Four specific abnormalities of timing of motion were studied during isovolumic contraction, early ejection, and isovolumic relaxation. Their timing and extent were all unaffected in postextrasystolic beats. These results thus give no evidence for the entity "reversible asynergy". Rather, they suggest that the response of local wall motion to postextrasystolic potentiation depends only on basal amplitude and increased volume change in postextrasystolic beats.

Regional left ventricular hypokinesis is a common manifestation of chronic ischaemic heart disease. In many cases, it is simply the result of scar tissue, but it has been suggested that its presence may also reflect potentially viable but poorly perfused myocardium, when it can be identified by an increase in its amplitude of motion in postextrasystolic beats. ${ }^{1-3}$ In previous investigations of this effect, estimates of wall motion have been based on the cavity outlines corresponding only to end-systole and end-diastole. In the present study, we have digitised all the cavity outlines of the cardiac cycle. We were thus able to avoid errors in measuring regional wall motion that arise when two frames only are used. ${ }^{4}$ We could also examine the possible effect of postextrasystolic potentiation in reversing regional abnormalities in the timing of wall motion, which, it has been suggested, may prove to be more sensitive indicators of ischaemia than a simple reduction in amplitude. ${ }^{3}$

Presented in part at the Meeting of the Working Groups of the European Society of Cardiology, Pavia, 1981.

Accepted for publication 3 February 1983

\section{Patients and methods}

We studied 18 patients undergoing left ventriculography and coronary arteriography for anginal pain, and an additional 12 at a study after saphenous bypass grafting as part of an investigation of the effects of myocardial revascularisation on regional left ventricular wall motion. All had significant coronary artery disease. Left ventriculography was performed in the right anterior oblique projection and, in 26 patients, simultaneous biplane right and left anterior oblique films were obtained. An injection of $45 \mathrm{ml}$ Urografin was given at a flow rate of 10 to $15 \mathrm{ml} / \mathrm{s}$ into the left ventricle, and cine film exposed at 50 frames/s. Calibration factors were calculated either using a grid at mid-chest level, or from measurement of tube-patient and tube-intensifier distances immediately after the procedure. Ectopic beats either occurred spontaneously, or were induced mechanically by manipulation of a catheter in the right ventricle. ${ }^{3}$ Multiple views of the right and left coronary arteries, and grafts when present, were then obtained using Judkins' technique.

ANALYSIS OF ANGIOGRAMS

Angiograms were digitised frame by frame. ${ }^{5}$ Plots 

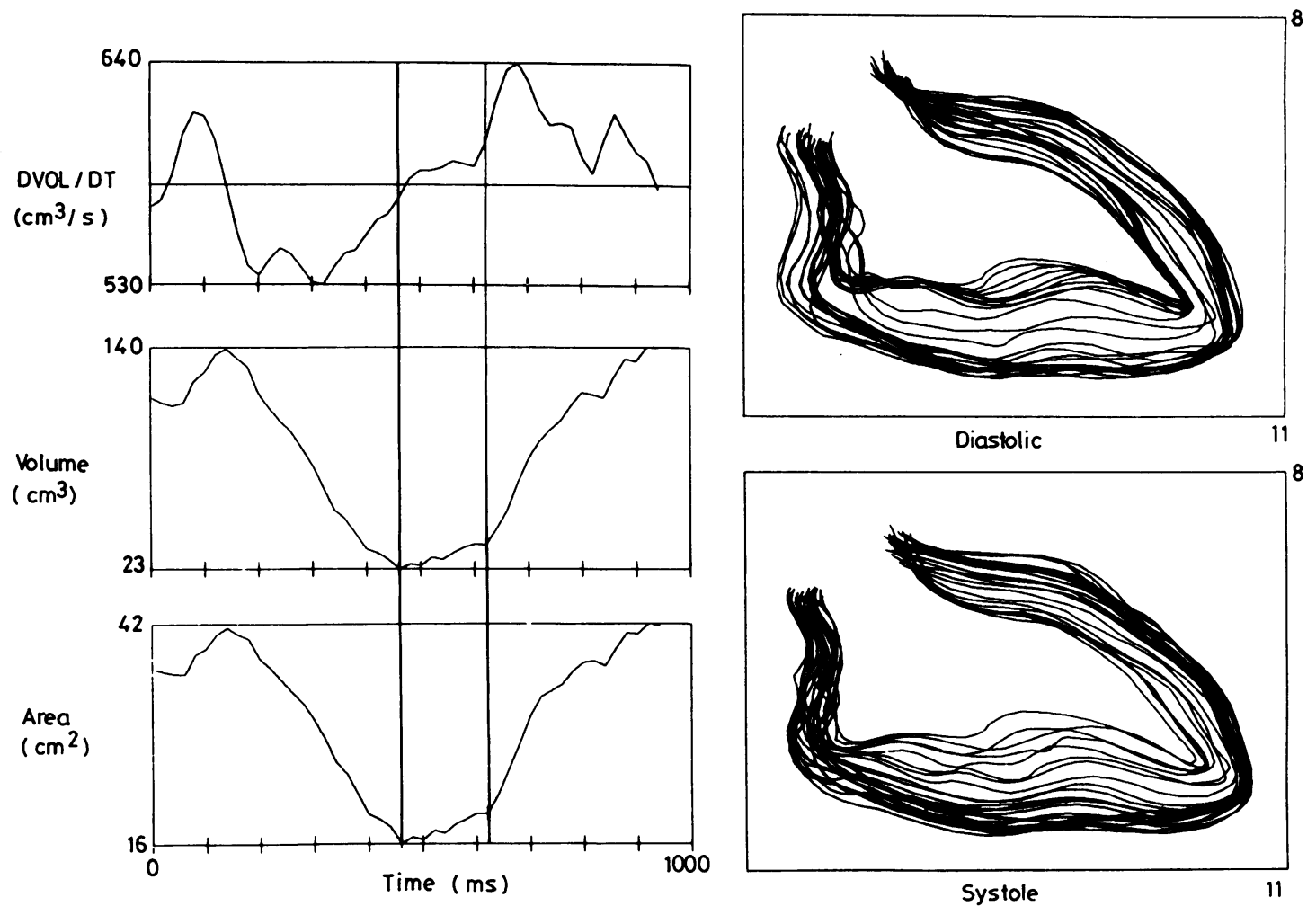

Fig. 1 Representative plots of changes in cavity area, volume, and rate of change of volume, and (right) superimposed cavity outlines during systole and diastole. The vertical lines represent the timing of minimum cavity area and mitral valve opening.

were made of superimposed cavity outlines during systole and diastole (Fig. 1). For each frame, cavity area was estimated, and volume calculated from the right anterior oblique projection, ${ }^{6}$ and plotted as a continuous curve, along with its first derivative, representing rate of change of volume. On each angiogram, the time of mitral valve opening was identified as that of the cine frame in which unopacified blood from the left atrium first appeared within the left ventricular cavity at the onset of diastole. This, and also the timing of minimum cavity area were superimposed on all plots, the interval between the two thus approximating to the period of isovolumic relaxation.

In each patient, measurements were made from a control and a postextrasystolic beat. Overall ventricular function was assessed from end-diastolic and endsystolic (minimum) volume. These were divided by body surface area to give the corresponding indices. Ejection fraction was calculated as stroke volume divided by end-diastolic volume. Peak rates of ejection and filling were derived as the corresponding rates of change of volume.

Regional wall motion was demonstrated by constructing contour displays for each beat. ${ }^{5}$ The method depends on multiple plots of endocardial movement against time derived from 40 equally spaced sites around the end-diastolic cavity outline, starting from the junction of the mitral valve and the aortic root and proceeding anticlockwise. Segments 1 to 19 thus represent the inferior wall of the ventricle, segment 20 the apex, and segments 21 to 40 the free wall. Analysis of regional wall motion was undertaken by constructing displays in which inward or outward movement of endocardium from its position in the end-diastolic frame was represented by a series of contour lines, each corresponding to motion of $1 \mathrm{~mm}$. Examples are given in Figs. 2-5. From these displays, the following information was derived.

(1) Sites and amplitude of regional hypokinesis, where the overall amplitude of motion during ejection was lower than the $95 \%$ confidence limit of normal for the particular region. Normal limits were determined from similar displays derived from 20 patients with the syndrome of chest pain and normal coronary arteriograms. The lower $95 \%$ confidence limit of normal ranged from 6 to $7 \mathrm{~mm}$ along the inferior wall, and from 7 to $9 \mathrm{~mm}$ along the free wall, in the right anterior oblique projection, and in the left anterior 




Fig. 2 Contour display of regional wall motion from a normal subject. For full description, see text.

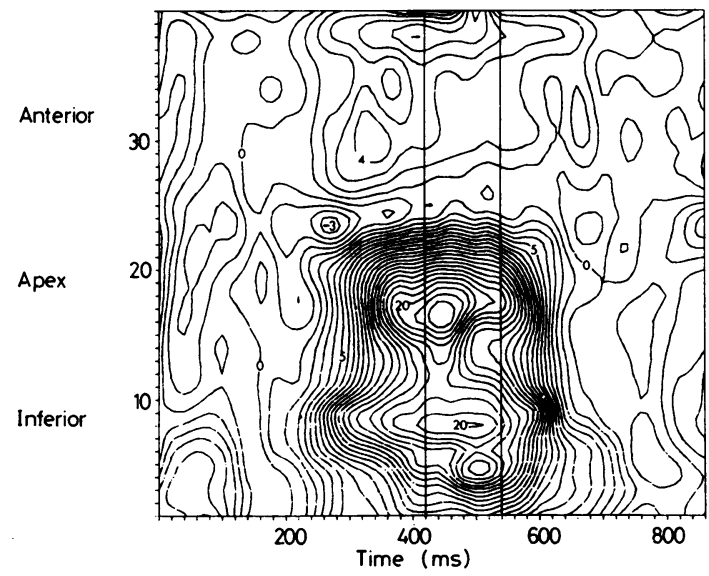

Fig. 3 Contour display of regional wall motion from a patient with anterior hypokinesis (right anterior oblique projection). For full description, see text.

oblique projection, was $8 \mathrm{~mm}$ along the posterior and inferior walls, and $5 \mathrm{~mm}$ on the anterior wall. The increase in the amplitude of wall motion caused by the ectopic beat was then correlated with overall amplitude of motion in the same region in the control beat. This relation was compared with the increase occurring in 40 normally moving segments, 20 from the anterior wall and 20 from the inferior wall.

(2) Segments showing abnormal ( $2 \mathrm{~mm}$ or more) outward movement of endocardium during early systole. ${ }^{7}$

(3) Segments showing abnormal prolongation, to more than $100 \mathrm{~ms}$ of the period covering the onset of inward wall motion in different regions of the cavity. ${ }^{8}$

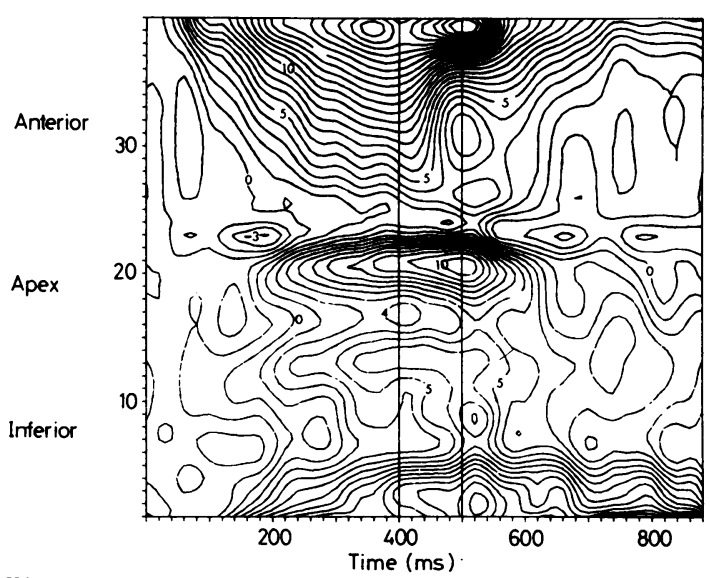

Fig. 4 Contour display of regional wall motion (control beat) from a patient with inferior hypokinesis, anterior asynchrony, anterior and inferior relaxation abnormalities, and disturbed filling pattern.

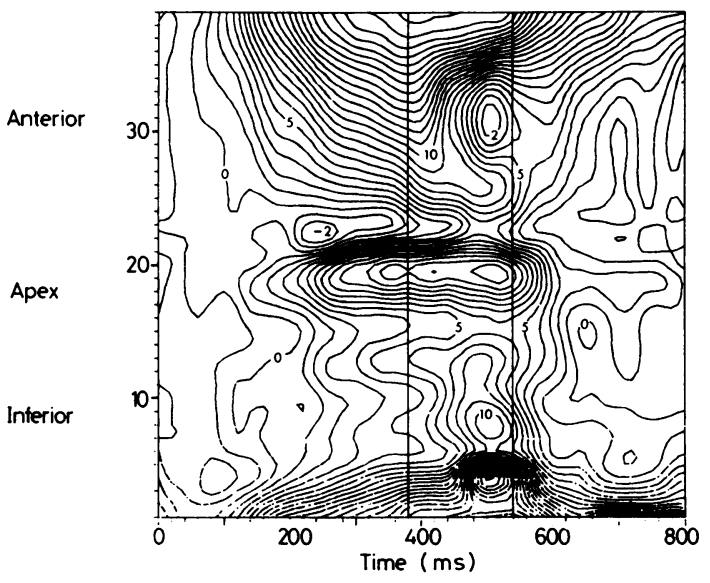

Fig. 5 Contour display of the same patient as in Fig 4, in a postextrasystolic beat. Note the similarity of regional wall motion to that in the control beat.

(4) Segments showing abnormal inward movement of $2 \mathrm{~mm}$ or more during isovolumic relaxation. 5

(5) Amplitude of abnormal outward movement of 7 $\mathrm{mm}$ or more during isovolumic relaxation, ${ }^{5}$ involving segments 25 to 40 along the free wall.

When comparing displays of control and postextrasystolic beats in individual patients, both the presence or absence of each specific abnormality was noted, and its distribution expressed as the range of segment numbers in which the criteria for its presence were satisfied, or its amplitude for outward motion during isovolumic relaxation, whose distribution to segments 25 to 35 was constant. (a) Agreement in demonstrating the abnormality, when the specific 
abnormality was present on both control and postextrasystolic beats, and its distribution differed by four segments or less, corresponding to $10 \%$ of the total perimeter; or (b) agreement in demonstrating the abnormality to be absent, when it was present on neither, or (c) control beat positive, when the specific abnormality was present on the display derived from the control beat, and not on that of the postextrasystolic; or (d) postextrasystolic beat positive, when the abnormality was present on the postextrasystolic beat display, but not on that from the control beat; or (e) a discrepancy, when both displays showed a similar abnormality of wall motion, but its distribution differed by more than four segments.

If two similar, non-overlapping disturbances of the same type were present on the same display, they were counted separately. Right and left anterior oblique projections were considered independently, so that there was a total of 56 comparisons for abnormalities of isovolumic relaxation, $\mathbf{5 7}$ for hypokinesis, 58 for isovolumic contraction, and 61 for asynchrony.

\section{REPRODUCIBILITY OF MEASUREMENTS}

In 15 patients, satisfactory opacification of the left ventricular cavity was obtained in two successive sinus beats. Both were therefore digitised in the right anterior oblique projection, and used to assess the reproducibility of measuring overall and local left ventricular function. Measurements of overall function were compared by calculation of within-patient standard deviation for end-diastolic and end-systolic volumes, and peak rates of change of volume during ejection and filling. Hypokinesis and each of the four specific abnormalities of regional wall motion were compared separately, and for each, the results were classified as showing the following. (i) Agreement, when both displays agreed in showing the abnormality to be present or absent, any discrepancy between the two in demonstrating its position being confined to four segments or less; or (ii) partial agreement, when the abnormality was shown to be present in overlapping regions in both displays, but with a discrepancy of more than four segments in defining its position; or (iii) discrepancy, when an abnormality was shown on only one display, or if it appeared in different and non-overlapping regions of the cavity in both. Statistical analysis was by Student's paired $t$ test or Fisher's exact probability test, as appropriate. Linear regression was performed by the method of least squares.

\section{Results}

OVERALL LEFT VENTRICULAR FUNCTION

In sinus beats, mean left ventricular end $\nsim$ diastolic volume was $189 \pm 46 \mathrm{ml}$ (end-diastolic volume index $101 \pm 23 \mathrm{ml} / \mathrm{m}^{2}$ ), falling to a minimum of $51 \pm 30 \mathrm{ml}$ $\left(27 \pm 16 \mathrm{ml} / \mathrm{m}^{2}\right)$, so that ejection fraction was $74 \pm 12 \%$ (mean \pm 1 standard deviation). Peak rate of reduction of ventricular volume during systole was $725 \pm 182$ $\mathrm{ml} / \mathrm{s}$, and the rate of increase during filling was similar, $680 \pm 215 \mathrm{ml} / \mathrm{s}$. Within-patient standard deviation, derived from sucessive control beats in 15 patients, was $7 \mathrm{ml}$ for end-diastolic volume and $4 \mathrm{ml}$ for end-systolic volume, corresponding to $2.4 \%$ for ejection fraction. Within-patient standard deviation for rates of change of volume was larger relative to control values, being $106 \mathrm{ml} / \mathrm{s}$ during ejection and 120 $\mathrm{ml} / \mathrm{s}$ during filling.

In postextrasystolic beats, end-diastolic volume was significantly larger than for the corresponding sinus beat, the mean increase being $10 \pm 16 \mathrm{ml}(\mathrm{p}<0.01)$. End-systolic volume was $8 \pm 10 \mathrm{ml}$ lower $(\mathrm{p}<0.001)$, so that ejection fraction increased by $7 \pm 8 \%$ $(p<0.001)$. There was also a significant increase in peak ejection rate of $120 \pm 185 \mathrm{ml} / \mathrm{s}(\mathrm{p}<0.01)$, and a smaller one in peak filling rate of $53 \mathrm{ml} / \mathrm{s}(p<0.05)$.

\section{REGIONAL LEFT VENTRICULAR FUNCTION}

An example of a normal pattern of wall motion is shown in Fig. 2. The amplitude of inward wall motion in any part of the cavity outline during the cardiac cycle can be derived from the number of $1 \mathrm{~mm}$ contour lines crossed by a horizontal line whose position on the display corresponds to the appropriate segment number. In the normal subject, the contours are almost vertical during systole, indicating synchronous onset of wall motion, though movement along the free wall (segments 21 to 40 ) characteristically precedes that along the inferior wall or apex. Changes in wall position during isovolumic relaxation are small, but there is synchronous outward movement after mitral valve opening, again shown by vertical contour lines. In the angiogram from which Fig. 3 is derived (case 28), the main abnormality is a reduction in the amplitude of wall motion in segments 25 to 38 , corresponding to the free wall. In these segments, the overall amplitude of motion is considerably less than $9 \mathrm{~mm}$, the lower limit of normal, so that such a region would be classified as hypokinetic. Segments 22 to 25 show 3 mm outward movement of endocardium in early systole, with reduced amplitude throughout the remainder of the cardiac cycle. Wall motion is normal over the remainder of the left ventricular outline (segments 1 to 21). In Fig. 4 (case 25), a different series of disturbances is present. Segments 5 to 17, involving the inferior wall, show hypokinesis. Motion is normal at the apex, but there is an area of outward motion of 3 $\mathrm{mm}$ in early systole involving segments 22 to 25 . Segments 5 to 17 also show delayed inward motion during isovolumic relaxation. Though the overall amplitude of inward motion is normal along the free wall (segments 25 to 40 ), the contour lines are dia- 
gonal, indicating asynchronous onset of contraction, with significant delay in the region of segments 22 to 28 , as well as on the inferior wall (6 to 18). In addition, there is some premature outward movement of endocardium ("segmental early relaxation phenomenon") 9 involving segments 30 to 35 , though this is less than $7 \mathrm{~mm}$, the upper $95 \%$ confidence limit of normal. The effect of these abnormalities on diastolic wall motion after mitral valve opening is also apparent, the only normal segments being 18 to 23 . This display should be compared with Fig. 5, from the corresponding postextrasystolic beat. There is a minor increase in the amplitude of systolic movement, and the extent of the outward movement during isovolumic relaxation has now increased to $10 \mathrm{~mm}$, but there is no other significant difference in the overall pattern of regional wall motion.

\section{REPRODUCIBILITY OF MEASUREMENTS OF REGIONAL MOVEMENT}

Reproducibility between successive sinus beats was assessed for each of the five abnormalities of wall motion separately. The results are shown in Table 1.

Table 1 Reproducibility of measurements of regional wall movement $(N=15)$

\begin{tabular}{llll}
\hline & Agreement & $\begin{array}{l}\text { Partial } \\
\text { agreement }\end{array}$ & Discrepancy \\
\hline $\begin{array}{c}\text { Regional } \\
\text { hypokinesis }\end{array}$ & 12 & 0 & 3 \\
$\begin{array}{c}\text { Isovolumic } \\
\text { contraction }\end{array}$ & 11 & 1 & 3 \\
$\begin{array}{c}\text { Asynchrony } \\
\text { Isovolumic } \\
\text { relaxation }\end{array}$ & 13 & 2 & 0 \\
$\quad \begin{array}{l}\text { Inward } \\
\text { Outward }\end{array}$ & 13 & 0 & 2 \\
\hline
\end{tabular}

In 59 out of 75 possible comparisons, there was complete agreement, and in a further three, there was partial agreement. Discrepancy was seen in 13. Of these, six involved regions of three segments or less in extent, and five were in the assessment of early outward movement during isovolumic relaxation. In four of these latter regions, the two measurements had differed by $2 \mathrm{~mm}$ or less, this difference being enough to bring one of the pair outside the normal range, while the other remained inside.

EFFECT OF POSTEXTRASYSTOLIC POTENTIATION ON REGIONAL WALL MOTION

Results of comparisons between sinus and postextrasystolic beats are given in Tables 2 and 3 . There was no significant difference in the effects of postextrasystolic potentiation in patients studied before and after coronary artery bypass grafting.
Table 2 Effect of postextrasystolic potentiation on regional wall movement

\begin{tabular}{llllll}
\hline & $\begin{array}{l}\text { Agree } \\
\text { absent }\end{array}$ & $\begin{array}{l}\text { Agree } \\
\text { present }\end{array}$ & $\begin{array}{l}\text { Control } \\
\text { positive }\end{array}$ & $\begin{array}{l}\text { PESB } \\
\text { positive }\end{array}$ & Discrepancy \\
\hline Hypokinesis & 30 & 20 & 6 & 0 & 1 \\
$\begin{array}{l}\text { Isovolumic } \\
\text { contraction }\end{array}$ & 28 & 15 & 6 & 5 & 4 \\
$\begin{array}{c}\text { Asynchrony } \\
\text { Isovolumic }\end{array}$ & 21 & 24 & 8 & 1 & 7 \\
$\begin{array}{c}\text { relaxation } \\
\text { Inward }\end{array}$ & 23 & 15 & 4 & 5 & 9 \\
$\quad$ Outward & 44 & 6 & 3 & 3 & 0 \\
\hline
\end{tabular}

^Postextrasystolic beat.

\section{Regional hypokinesis}

Areas of regional hypokinesis were present in at least one projection in the control beats of 17 patients. In the corresponding postextrasystolic beats, six of these regions had reverted to within the normal range for control beats. The relation was observed between the amplitude of movement of hypokinetic segments in control beats and their increase in postextrasystolic beats. This was compared with the corresponding increase in normally moving segments. The results are shown in Fig. 6. Postextrasystolic stimulation caused a significant increase in the amplitude of normally moving segments, given by the relation:

Amplitude (PEB) $=0.91$ (amplitude (CB)) $+5.7 \mathrm{~mm}$, where amplitude (PEB) and amplitude (CB) represent the overall amplitude of regional wall motion during ejection in the postextrasystolic and control beats, respectively. The standard error of the estimate was $2.8 \mathrm{~mm}$. The slope of the relation did not differ significantly from 1 , but the intercept, $5.7 \mathrm{~mm}$, was significantly different from zero $(p<0.01)$. In normal segments, therefore, postextrasystolic potentiation causes an increase in the amplitude of local wall motion of approximately $6 \mathrm{~mm}$, regardless of the initial value. The effect of postextrasystolic potentiation of hypokinetic segments is also shown in Fig 6. An increase in amplitude of movement of $3 \mathrm{~mm}$ or above, the lower $95 \%$ confidence limit for the increase in normals, was seen in the majority of segments moving by $5 \mathrm{~mm}$ or more, whereas the increase was significantly less or absent altogether in segments moving $4 \mathrm{~mm}$ or less in the sinus beat.

Abnormal outward movement during early systole

This abnormality was present in the control beat in 18 patients. Its pattern changed little in postextrasystolic beats. In 28 instances, both control and postextrasystolic beats showed no abnormality. In 15 comparisons, a similar abnormality was present in both. In 14 instances there was disagreement, but there was no evidence to suggest that this occurred preferentially under either condition, since in six cases it was pres- 
Table 3A Segmental wall movement $R A O$ projection, control beat distribution of abnormal segments

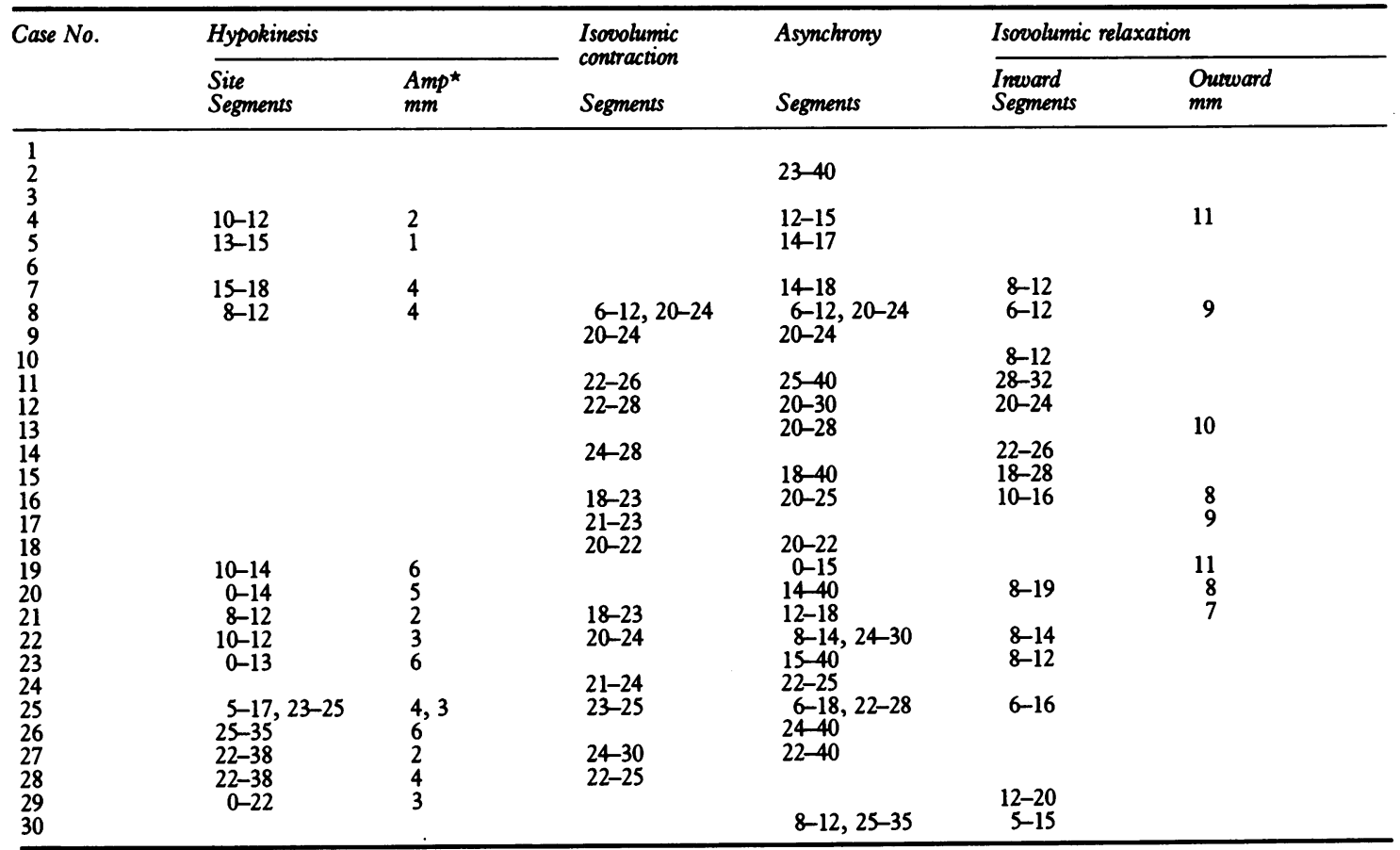

*Amplitude of movement.

Table 3B Segmental wall movement RAO projection, postextrasystolic beat distribution of abnormal segments

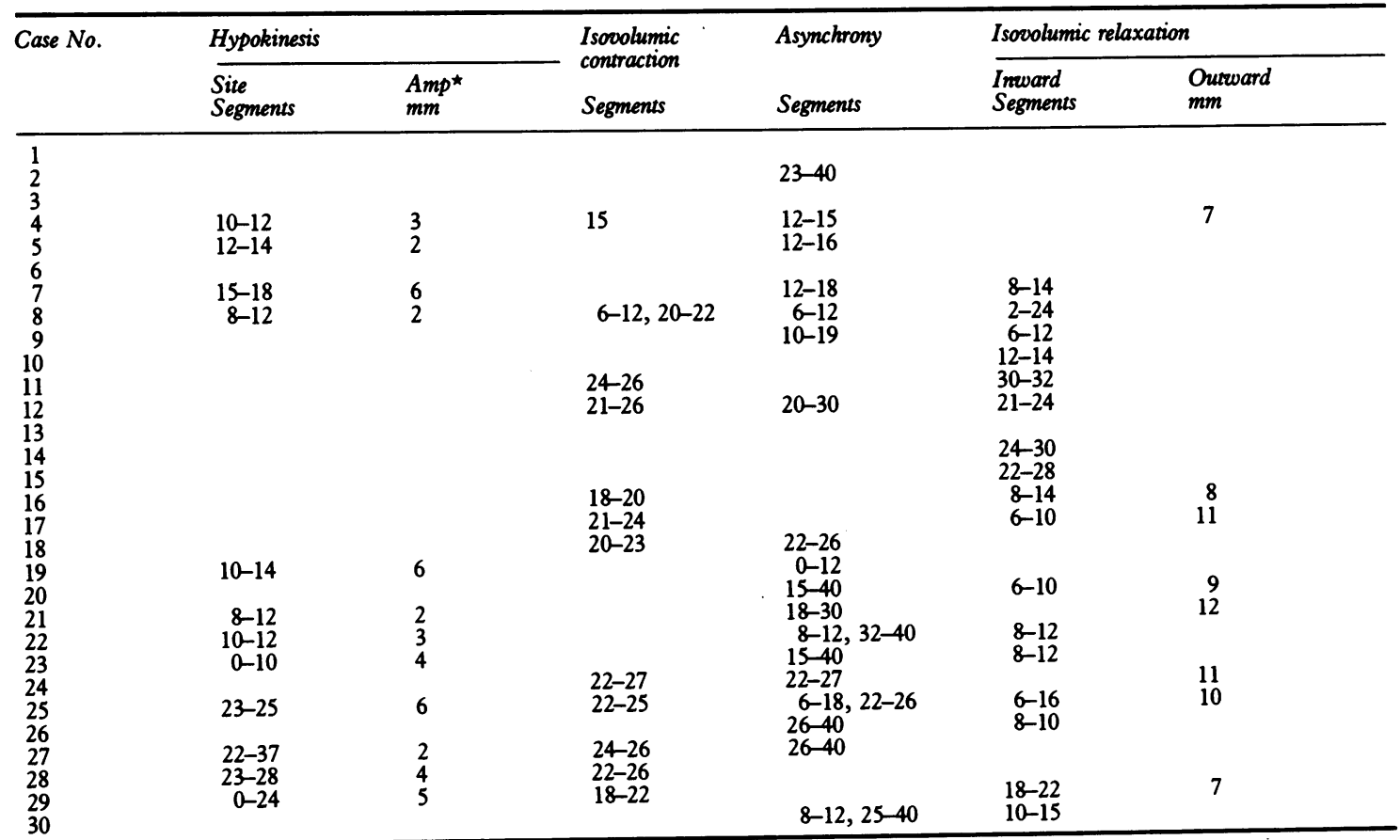

$\star$ Amplitude of movement. 
Table 3C Segmental wall movement LAO projection, control beat

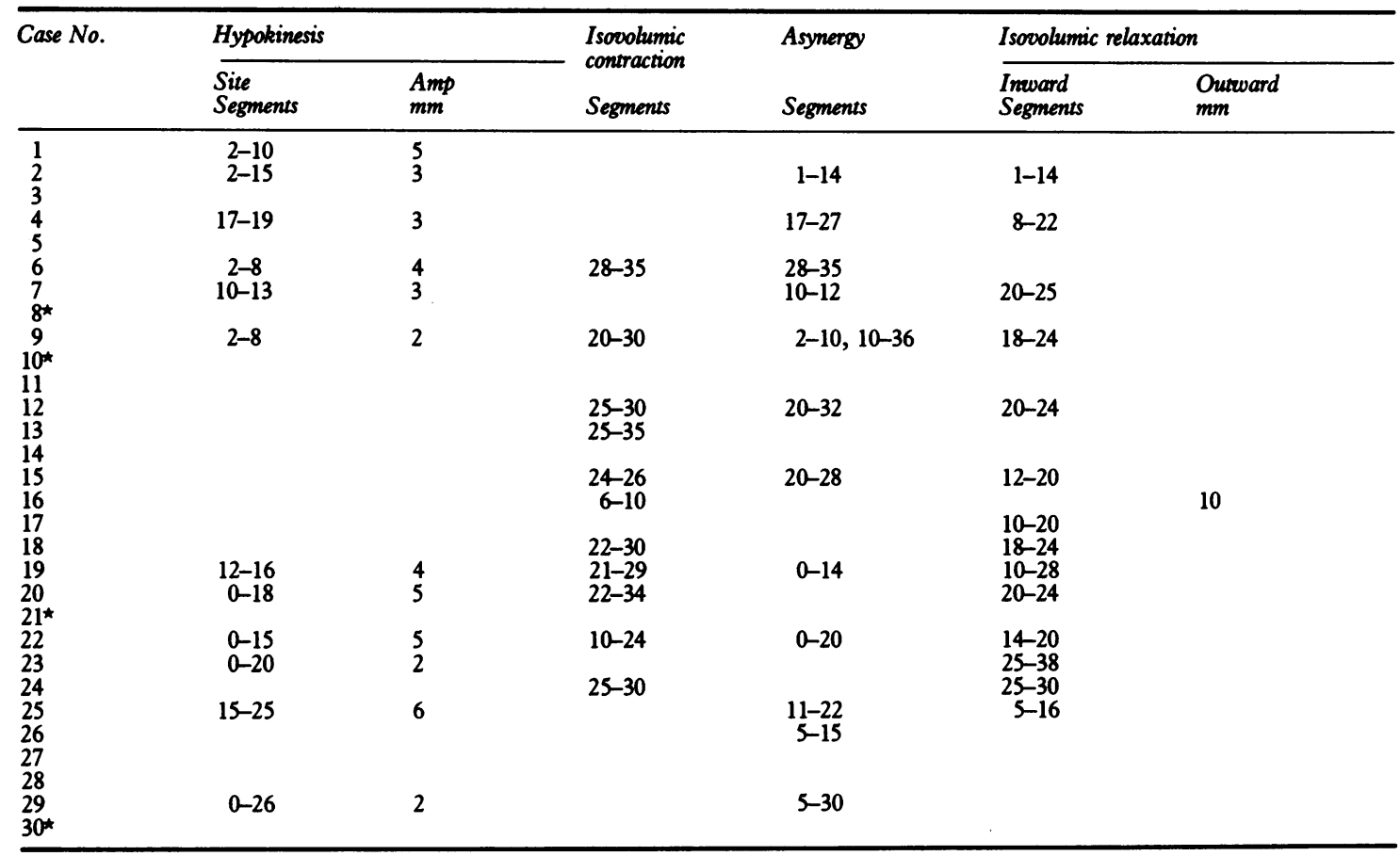

$\star$ LAO projection not available in these cases.

Table 3D Segmental wall movement LAO projection, postextrasystolic beat

\begin{tabular}{|c|c|c|c|c|c|c|}
\hline \multirow[t]{2}{*}{ Case No. } & \multicolumn{2}{|c|}{ Hypokinesis } & \multirow{2}{*}{$\begin{array}{l}\text { Isooolumic } \\
\text { contraction } \\
\text { Segments }\end{array}$} & \multirow{2}{*}{$\begin{array}{l}\text { Asynchrony } \\
\text { Segments }\end{array}$} & \multicolumn{2}{|c|}{ Isovolumic relaxation } \\
\hline & $\begin{array}{l}\text { Site } \\
\text { Segments }\end{array}$ & $\underset{m m}{A m p}$ & & & $\begin{array}{l}\text { Inward } \\
\text { Segments }\end{array}$ & $\begin{array}{l}\text { Outward } \\
\text { mm }\end{array}$ \\
\hline \multirow{11}{*}{$\begin{array}{l}1 \\
2 \\
3 \\
4 \\
5 \\
6 \\
7 \\
8^{\star} \\
9 \\
10^{\star} \\
11 \\
12 \\
13 \\
14 \\
15 \\
16 \\
17 \\
18 \\
19 \\
20 \\
21^{\star} \\
22 \\
23 \\
24 \\
25 \\
26 \\
27 \\
28 \\
29 \\
30^{\star}\end{array}$} & $2-10$ & 5 & & & & \multirow{11}{*}{10} \\
\hline & $16-18$ & 2 & & $18-25$ & & \\
\hline & $2-6$ & 4 & $18-32$ & $12-20$ & $22-26$ & \\
\hline & $2-8$ & 4 & $18-30$ & $2-12$ & $15-30$ & \\
\hline & & & $24-28$ & $10-14$ & $25-32$ & \\
\hline & & & & $20-30$ & $10-22$ & \\
\hline & & & $\begin{array}{r}6-10 \\
18-26 \\
10-14\end{array}$ & & $\begin{array}{r}17-23 \\
8-20\end{array}$ & \\
\hline & $\begin{array}{r}15-20 \\
0-14\end{array}$ & $\begin{array}{l}5 \\
3\end{array}$ & $\begin{array}{l}20-23 \\
20-32\end{array}$ & $0-14$ & $\begin{array}{l}20-30 \\
18-22\end{array}$ & \\
\hline & $\begin{array}{l}0-15 \\
0-18\end{array}$ & $\begin{array}{l}3 \\
4\end{array}$ & $\begin{array}{l}14-20 \\
14-20 \\
8-12\end{array}$ & $0-20$ & $\begin{array}{l}15-20 \\
25-40\end{array}$ & \\
\hline & & & $22-28$ & $\begin{array}{r}10-22 \\
0-10 \\
0-15\end{array}$ & $12-18$ & \\
\hline & $0-26$ & 6 & & $0-27$ & $2-10$ & \\
\hline
\end{tabular}




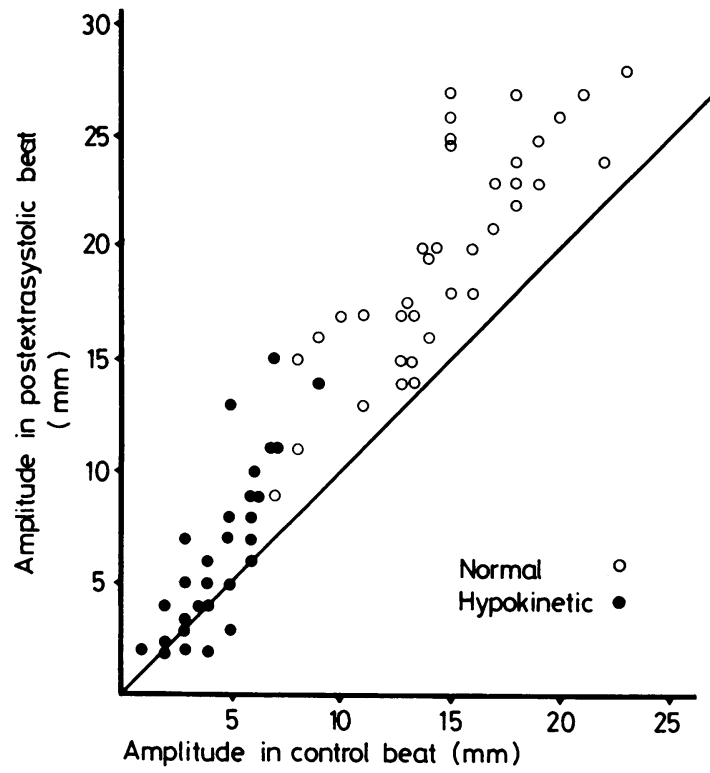

Fig. 6 Effect of postextrasystolic potentiation on systolic amplitude of movement of normal and hypokinetic segments. The increase in amplitude in the postectopic beat with respect to the control beat is shown. Normal and abnormal segments are defined in terms of $95 \%$ confidence limits for the region in question. The line of identity is shown. Note that there is a uniform increase in amplitude of approximately $6 \mathrm{~mm}$ for normal segments, while it is consistently reduced in those showing hypokinesis in the control beat.

ent in the control beat only, in five in the postextrasystolic beat, and in four the abnormality was present in both, but with a significant discrepancy as to its position.

\section{Delayed onset of inward movement}

In sinus beats, asynchrony of early systolic wall motion was common, occurring in 25 out of the 30 patients in the control beat. Control and postextrasystolic beats agreed in 45 comparisons in showing either the absence or the presence and site of delayed onset of inward wall motion. In eight patients, the abnormality was present in the control beat only, and in one the reverse was seen. There was a significant discrepancy in seven as to position.

Premature early outward wall motion during isovolumic relaxation

This was present in the control beat in eight patients, all shown in the right anterior oblique projection, and in all involving the middle and high anterior wall (segments 25 to 35). In six of these comparisons, it was also present in the postextrasystolic beat. It was absent in the control beat in 44 , and in all but three of these in the postextrasystolic beat.

\section{Abnormal inward motion during isovolumic relaxation by $2 \mathrm{~mm}$ or more}

This was a common finding, being present in 22 patients in one or both projections in the control beat. Disagreement was seen on 18 comparisons: in four the abnormality was present in the control beat and not in the postextrasystolic, in five it was present in the postextrasystolic and not in the control beat; in nine it was present in both, but with a significant discrepancy as to its position. There was no significant difference in amplitude or timing of the peak of abnormal inward motion during isovolumic relaxation in the postextrasystolic beat compared with the control.

\section{Discussion}

Regional wall motion in ischaemic heart disease is complex, involving abnormalities of timing as well as amplitude and direction of movement. Previous studies of the effect of postextrasystolic potentiation on contraction pattern have assessed regional wall motion by comparing the position of the cavity boundary at end-diastole and end-systole, ${ }^{1-3}$ a method capable only of demonstrating regional changes in amplitude. This "two frame" method, however, cannot be used when cavity shape changes during isovolumic relaxation because of asynchronous termination of systole in different regions of the ventricle. ${ }^{4}$ End-systole is not a clearly defined event in these circumstances but extends throughout the period of isovolumic relaxation at a time when significant regional wall motion is occurring. Variation in the timing of the "end-systolic" frame thus has a very significant effect on the apparent pattern of wall motion displayed by the two frame method. Unfortunately, minimum cavity area, particularly when determined by simple inspection of the film, is an unreproducible landmark of aortic valve closure, while to take endsystole as the time when all inward movement has ceased $^{10}$ makes it very likely that in a significant proportion of patients with ischaemic heart disease, premature outward movement will have already started elsewhere in the cavity. We have therefore circumvented this problem by digitising all frames in a single cardiac cycle, a method that also allowed us to study disorders in the timing of movement as well as of its extent. The method of analysis divides the cavity perimeter into $\mathbf{4 0}$ segments, allowing disturbances to be localised more precisely than with four quadrants or six hemiaxes. Wall motion itself was measured approximately perpendicular to the wall, rather than by using a rectilinear grid or a series of radial lines originating from some point within the cavity, both of 
which may be oblique to myocardium in some regions of the wall. Since information about reproducibiity of measurement of overall and regional wall motion was available, it was possible to quantify wall motion rather than simply to detect the presence or absence of hypokinesis, using $95 \%$ confidence limits derived from normal ventriculograms, analysed by the same method.

Comparison of overall left ventricular function shows clear evidence of potentiation after ectopic beats. End-diastolic volume was increased and endsystolic volume was smaller, with a significant increase in ejection fraction. Peak rates of ejection and, to a lesser extent, of filling also increased. At least three mechanisms are likely to have been involved: increased end-diastolic cavity size, reduced arterial pressure after a postextrasystolic pause, and the positive inotropic effect of a sudden increase in $R R$ interval. It would thus be anticipated that these global changes would be reflected in local function, and such was the case. In $\mathbf{4 0}$ normal regions, the amplitude of wall motion was increased by 4 to $7 \mathrm{~mm}$, regardless of the initial amplitude. The effect on areas that were hypokinetic in the control state was significantly different. In a number of them, the amplitude of wall motion was increased in the postextrasystolic beat, as has previously been reported. ${ }^{1-3}$ In these, however, the amplitude in the control beat was $5 \mathrm{~mm}$ or more, while in those where the amplitude was $4 \mathrm{~mm}$ or less it uniformly failed to increase by a normal amount (Fig. 6). Though there was some variability in response, it simply appeared to be a function of the reproducibility of the method as manifested in both normal and hypokinetic regions, and not to represent any significant difference in biological response between segments. The change in amplitude after the postextrasystolic beat could thus be directly predicted from the basal contraction pattern, without the need to invoke additional information based, for example, on the perfusion of the segment under consideration. Associated with this increase in amplitude was an improvement in the synchrony of wall motion in different regions of the cavity. Asynchrony appears to be a non-specific manifestation of left ventricular disease, as it also occurs in left ventricular hypertrophy, ${ }^{8}$ so that its lessening in postextrasystolic beats cannot be taken as evidence for any improvement in ischaemia.

In vitro experiments have shown that a reduction in amplitude of contraction is not the first mechanical abnormality to appear with the onset of ischaemia, but that it is frequently preceded by prolongation of contraction and delay in the onset of relaxation. ${ }^{10} \mathrm{It}$ has been suggested that postextrasystolic potentiation reverses the effects of myocardial ischaemia. ${ }^{3}$ Thus, if the mechanism underlying the abnormalities of wall motion seen in chronic ischaemic heart disease is the same as in acute animal experiments, any delay in the onset of relaxation should also be reversed by postextrasystolic potentiation. The present study gave no support to this suggestion. Though prolonged inward motion was frequently seen in the angiograms of the patients studied, in the large majority of cases its presence, distribution, and timing were unaffected in the postextrasystolic beat. Differences between control and postextrasystolic beat, when they occurred, were infrequent and inconsistent, and again showed an incidence compatible with the reproducibility of the method used to detect them. Early outward wall motion during isovolumic relaxation occurs in otherwise normal regions of diseased ventricles, and is associated with abnormal delay in relaxation elsewhere in the wall..$^{5}$ Its constancy in postextrasystolic beats again suggested that no consistent alteration in the regional pattern of relaxation was occurring in postextrasystolic beats. Regional abnormalities of systole were also largely unaffected. Outward movement during early systole appears to result from delay in the onset of tension development, ${ }^{7}$ though whether this is the result of delayed activation of abnormal electromechanical coupling is unknown. This abnormality, also characteristic of coronary artery disease, was similarly unaffected by postextrasystolic potentiation. We were thus unable to find any evidence of change in specific abnormalities in the timing of wall motion that would suggest that the effects of local ischaemia had in any way been modified, still less mitigated or reversed.

Our observations are thus in line with those of Schwarz et al. ${ }^{11}$ who previously reported a similar increase in the amplitude of both hypokinetic and normal axes of diseased ventricles of the same order as those we observed. They differ, however, from the results of a number of other studies ${ }^{1-312^{-15}}$ which have all shown a striking increase in certain hypokinetic segments in postextrasystolic beats. We suggest that this apparent difference may reflect the method used to analyse regional wall motion. Regional wall motion during isovolumic relaxation is frequently incoordinate, ${ }^{5}$ with early outward movement occurring particularly commonly along the free wall. ${ }^{16}$ Any delay in the timing of the end-systolic frame would thus cause an apparent reduction in the amplitude of wall movement in this part of the ventricle. An example from the present patients is given in Fig. 7, showing a striking change in the apparent pattern of motion dependent on the timing of the end-systolic frame, indicating how such errors can arise. Evidence has been presented elsewhere ${ }^{5}$ to suggest that regions showing early outward motion are not directly affected by the ischaemic process. Their normal perfusion $^{13}$ and frequently normal histological struc- 

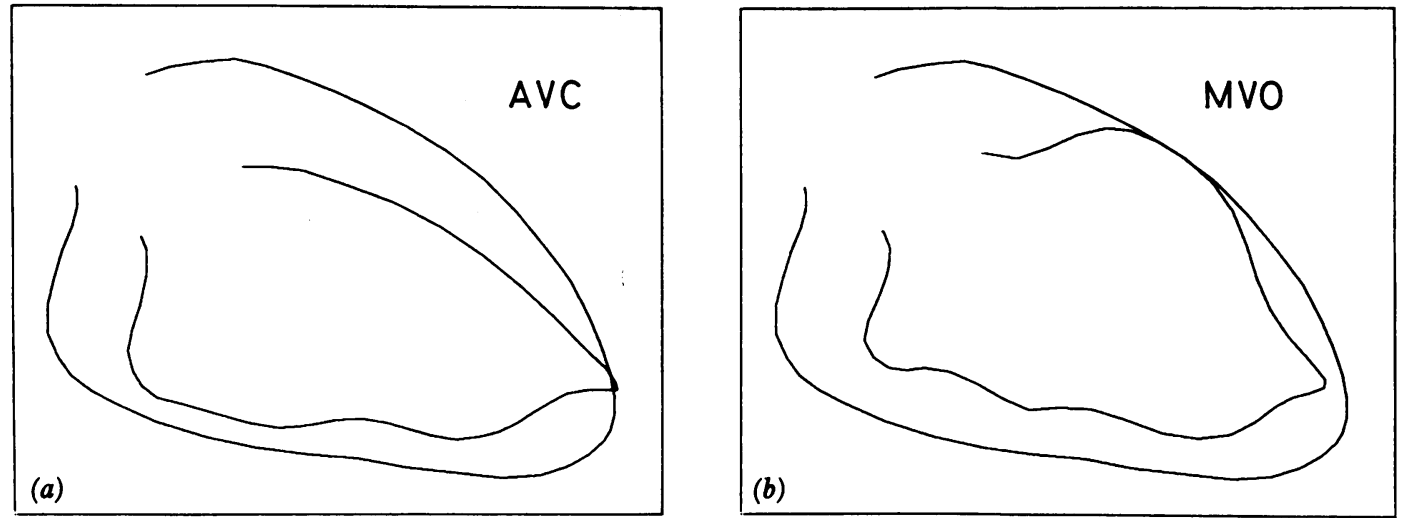

Fig. 7 Two displays of regional wall motion from the same beat, using the "two frame" technique. The end-diastolic frame is the same in both, but end-systole is taken as the timing of aortic valve closure in (a), and of mitral valve opening in (b). Note the difference in the apparent pattern of wall motion, caused by early outward movement of the free wall and prolonged inward movement of the inferior wall.

ture ${ }^{17} 18$ are not therefore unexpected. In addition, the three studies in which detailed topographical information is given 121315 demonstrate that the apparent improvement in wall motion with revascularisation is significantly greater on the anterior wall of the left ventricle compared with the inferior on the right anterior oblique projection. If this explanation is incorrect, some other basis must be found for the predilection of "reversible asynergy" for the anterior wall of the heart.

We conclude therefore that the "two frame" technique is inadequate to analyse the complex disturbances of wall motion seen in patients with chronic coronary artery disease, and that information from all frames must be used. With this latter approach, the effects of postextrasystolic potentiation are seen to be non-specific, depending only on the increase in cavity volume change. Regions with moderate hypokinesis behave in the same was as normal ones. It is only those regions with absent or greatly reduced wall motion in the control beat, probably caused by fibrous replacement of myocardium, that show small increases in the postextrasystolic beat and that fail to improve after surgery. It seems, therefore, that abnormal wall motion in the left ventricle in patients with chronic ischaemic heart disease differs fundamentally from that seen in the acutely ischaemic animal preparation, 1920 and that direct extrapolation of these experimental results to the setting of chronic coronory artery disease is likely to prove unfruitful.

\section{References}

1 Dyke SH, Cohn PF, Gorlin R, Sonnenblick EH. Detection of residual myocardial function in coronary artery disease using post-extra systolic potentiation. Circulation 1974; 50: 694-9.

2 Hamby RI, Aintablian A, Wisoff BG, Hartstein ML. Response of the left ventricle in coronary artery disease to postextrasystolic potentiation. Circulation 1975; 51: 428-35.

3 Cohn PF. Evaluation of inotropic contractile reserve in ischemic heart disease using postextrasystolic potentiation. Circulation 1980; 61: 1071-5.

4 Marier DL, Gibson DG. Limitations of two frame method for displaying regional left ventricular wall motion in man. Br Heart $\mathcal{F} 1980$; 44: 555-9.

5 Gibson DG, Prewitt TA, Brown DJ. Analysis of left ventricular wall movement during isovolumic relaxation and its relation to coronary artery disease. $B r$ Heart $\mathcal{F} 1976$; 38; 1010-9.

6 Sandler H, Dodge HT. The use of single plane angiocardiograms for the calculation of left ventricular volume in man. Am Heart f 1968; 75: 325-34.

7 Gibson DG, Doran JH, Traill TA, Brown DJ. Abnormal left ventricular wall movement during early systole in patients with angina pectoris. Br Heart $\mathcal{F}$ 1978; 40: 75866.

8 Gibson DG, Sanderson JE, Traill TA, Brown DJ, Goodwin JF. Regional left ventricular wall movement in hypertrophic cardiomyopathy. Br Heart $\mathcal{f}$ 1978; 40: 1327-33.

9 Hamby RI, Aintablian A, Tabrah F, Reddy K, Wisoff G. Late systolic bulging of left ventricle in patients with angina pectoris. Chest 1974; 65: 169-75.

10 Tyberg JV, Parmley WW, Sonnenblick EH. In-vitro studies of myocardial asynchrony and regional hypoxia. Circ Res 1969; 25: 569-79.

11 Schwarz F, Ensslen R, Thormann J, Sesto M. Effects of nitroglycerin, postextrasystolic potentiation and pacinginduced ischaemia on wall motion in patients with ischaemic heart disease. Br Heart $\mathcal{F}$ 1977; 39: 44-52.

12 Popio KA, Gorlin R, Bechtel D, Levine JA. Postextrasystolic potentiation as a predictor of potential 
myocardial viability: preoperative analyses compared with studies after coronary bypass surgery. Am $\mathcal{F}$ Cardiol 1977; 39: 944-53.

13 See JR, Cohn PF, Holman BL, Adams DF, Maddox DE. Sigificance of reduced regional myocardial blood flow in asynergic areas evaluated with intervention ventriculography. Results of studies combining washout of xenon-133 and postextrasystolic potentiation. $\mathrm{Am} \mathcal{F}$ Cardiol 1979; 43: 179-85.

14 Klausner SC, Ratshin RA, Tyberg JV, Lappin HA, Chatteriee K, Parmley WW. The similarity of changes in segmental contraction patterns induced by postextrasystolic potentiation and nitroglycerin. Circulation 1976; 54: 615-23.

15 Banka VS, Bodenheimer M, Shah R, Helfant RH. Intervention ventriculography: comparative value of nitroglycerin, post-extrasystolic potentiation and nitroglycerin plus post-extrasystolic potentiation. Circulation 1976; 53: 632-7.

16 Greenbaum RA, Gibson DG. Regonal non-uniformity of left ventricular wall movement in man. $B r$ Heart $\mathcal{F} 1981$; 45: 29-34.
17 Stinson EB, Billingham ME. Correlative study of regional left ventricular histology and contractile function. Am $\mathcal{F}$ Cardiol 1977; 39: 378-83.

18 Bodenheimer MM, Banka VS, Hermann GA, Trout RG, Pasdar H, Helfant RH. Reversible asynergy. Histopathological and electrographic correlations in patients with coronary artery disease. Circulation 1976; 53: 792-6.

19 Diamond GA, Forrester JS, deLuz PL, Wyatt HL, Swan HJC. Post-extrasystolic potentiation of ischemic myocardium by atrial stimulation. Am Heart $\mathcal{f} 1978$; 95: 204-9.

20 Boden WE, Liang C-S, Hood WP Jr. Postextrasystolic potentiation of regional mechanical performance during prolonged myocardial ischemia in the dog. Circulation 1980; 61: 1063-70.

Requests for reprints to Dr G Gibson, Cardiac Department, Brompton Hospital, Fulham Road, London SW3 6HP. 